\section{P73 EPIDEMIOLOGY AND LONG TERM OUTCOMES OF PATIENTS WITH CHRONIC OBSTRUCTIVE PULMONARY DISEASE ADMITTED TO SCOTTISH INTENSIVE CARE UNITS}

doi:10.1136/thoraxjnl-2011-201054c.73

${ }^{1} \mathrm{~N}$ I Lone, ${ }^{1} \mathrm{D}$ A McAllister, ${ }^{2} \mathrm{~K}$ M Rowan, ${ }^{1} \mathrm{~T}$ S Walsh, ${ }^{1} \mathrm{~S} \mathrm{H}$ Wild, ${ }^{1} \mathrm{G} \mathrm{D}$ Murray. ${ }^{1}$ University of Edinburgh, Edinburgh, UK; ${ }^{2}$ Intensive Care National Audit and Research Centre, London, UK

Introduction Patients admitted to intensive care units (ICUs) with an exacerbation of chronic obstructive pulmonary disease (COPD) are thought to have poor outcomes. Few studies have reported the impact of ICU admission on long-term outcomes. We aimed to describe the epidemiology of patients admitted to all Scottish ICUs with an exacerbation of COPD, and to ascertain the importance of admission on long-term mortality and hospital readmission rates.

Methods We used a retrospective cohort design linking the Scottish Intensive Care Society Audit Group national database of ICU admissions to the national Scottish hospital discharges and death registry databases. The study cohort comprised all patients admitted to Scottish ICUs in 2005 aged $=35$ years with a primary ICU admission diagnosis of COPD, or respiratory infection/sepsis as the primary and COPD as the secondary diagnosis. Mortality was defined as death within 4 years of ICU admission. Logistic regression identified factors independently associated with mortality. Hospital readmission rates for the 3 years prior to and following discharge from the index hospitalisation were calculated.

Results 249 of 7727 (3.2\%) first admission episodes to Scottish ICUs in 2005 were with an exacerbation of COPD. Mean age: 67 years; female: 52\%; median admission Simplified Acute Physiology Score II: 35 (IOR 26-45). 83\% of patients received mechanical ventilation; $24 \%$ required tracheostomy. Mean duration of ICU and hospital stays: 6.9 and 28.0 days, respectively. Mean duration of ventilation: 5.7 days (ICU survivors 5.9, non-survivors 5.2). Mortality at ICU and hospital discharge was $23.8 \%$ and $34.7 \%$, respectively. It was $46.4 \%$ at 1 year and $66.1 \%$ at 4 -year spost-ICU admission. Only age $(p<0.001)$ and previous COPD admission $(p=0.01)$ were independently associated with 4-year mortality. The mean hospital readmission rate during the 3-year follow-up period was twice that of the period before index hospitalisation (1.4 vs 0.7 readmissions/person-year for all admissions, 0.7 vs 0.3 for COPD admissions, Abstract P73 figure 1).

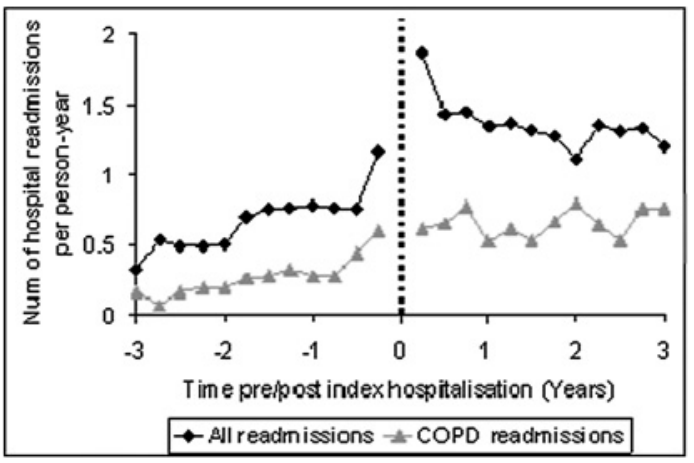

Abstract P73 Figure 1 Hospital readmission rates before and after ICU admission due to exacerbation of COPD. Data points are number of readmissions per person-year for each 3-month period. For the postindex hospitalisation period, the person-year denominator includes only those alive at the start of each 3-month period.

Conclusion This Scottish national cohort had comparable shortterm mortality rates to those seen in a general ICU population. The poorer long-term mortality rate and increased readmission rates after hospital discharge may be useful to consider alongside other factors when deciding on ICU admission for patients with COPD.

\section{P74 EMERGENCY OXYGEN USAGE OBSERVED BY A MEDICAL EMERGENCY TEAM}

doi:10.1136/thoraxjnl-2011-201054c.74

J Carr, J Rodrigues, N Duffy, J Earis. University Hospital Aintree, Liverpool, UK

Introduction Aintree University Hospital was one of the first acute Trusts to develop a multidisciplinary MET team in the UK. It was created in 2009 to manage acutely ill and deteriorating patients safely in keeping with the NICE 50 (2007) guidance. The MET team records data on each callout and this study analyses the use of oxygen in this cohort of patients.

Methods The MET team records (1) any patient who is not on O2 with an SpO2 below $94 \%$ and (2) patients already on oxygen with a low SpO2 necessitating a change in flow rates. Following the experience of the first 6 months a simple laminated sheet outlining the actions needed before the MET team is called was prepared for all wards. This clearly states the BTS target ranges for $\mathrm{SpO} 2$ and oxygen prescription. This aide memoire was in use for 12 months before the second 6-month analysis period.

Results In the 19 months of its existence the MET has responded to 1717 calls. Of these 536 patients needed $\mathrm{O} 2$ initiating (32\%) because of low SpO2 and a further 685 had the $\mathrm{O} 2$ flows changes (38\%). The Abstract P74 table 1 shows comparison between the first 6 months with the 6 months to April 2011 (post educational intervention). The number of calls has increased between these two time blocks from an average of 2.44 to 3.33 per day and the number of patients who needed oxygen starting decreased from $38 \%$ to $29 \%$.

\section{Abstract P74 Table 1}

\begin{tabular}{llll}
\hline & Total Calls & 02 Started & 02 changed \\
\hline Initial 6 months & 444 & $169(38 \%)$ & $187(42 \%)$ \\
Post Intervention 6 months & 538 & $159(29 \%)$ & $217(41 \%)$ \\
\hline
\end{tabular}

Conclusions This study confirms the results of the BTS National Audits 2008 and 2010 and the NPSA Rapid response Report September 2009 that emergency oxygen is poorly administered in the NHS. The simple intervention of providing an aide memoire on the wards has improved the situation but it still remains unsatisfactory. Because of this UHA has now introduced a new Patient Group Direction for the administration of $\mathrm{O} 2$ by first level registered nurses. This will empower nurses to initiate oxygen in deteriorating patients with a low $\mathrm{SpO} 2$ while waiting for assistance from the MET team

\section{P75 TEACHING EMERGENCY OXYGEN PRESCRIBING TO MEDICAL STUDENTS}

doi:10.1136/thoraxjnl-2011-201054c.75

${ }^{1} \mathrm{~J}$ Earis, ${ }^{2} \mathrm{P}$ Deegan, ${ }^{3} \mathrm{P}$ Stockton, ${ }^{4} \mathrm{~S}$ McKinnell, ${ }^{4} \mathrm{R}$ Fewtrell, ${ }^{4} \mathrm{~T}$ Kennedy. ${ }^{1}$ University Hospital Aintree, Liverpool, UK; ${ }^{2}$ Royal Liverpool University Hospital, Liverpool, UK; ${ }^{3}$ Whiston Hospital, Liverpool, UK; ${ }^{4}$ University Of Liverpool, Liverpool, UK

Introduction In 2008 the BTS published the first National Emergency Oxygen Guidance. Subsequent national audits in 2008 and 2010 have shown poor compliance with these guidelines. In order to improve the use of emergency oxygen Liverpool Medical School has included this topic in a new Patient Safety Programme (PSP) developed to provide practical skills for the 335 fifth year students as a preparation for their Foundation Programme.

Methodology (1)Computer based knowledge test (CBKT) of 60 $\mathrm{MCQ}$ questions, based on the BTS guidance and BNF are accessed on-line by the students. Each student has to correctly answer $80 \%$ of 
10 randomly selected questions. (2) Practical oxygen management session including demonstration of oxygen delivery systems and blood gas sampling in a Clinic Skills Department. (3) Ward based supervised skills including completion of five oxygen prescriptions and blood gas samples.

Results The CBKT score was low with an average of 6.2 of 10 questions answered correctly after the first attempt. After 10 attempts only $72 \%$ students passed thus $28 \%$ (94 students) were unable to reach the pass threshold. The Abstract P75 table 1 relates the pass rate to the numbers of attempts shows only a modest incremental increase in the cumulative pass rate. In contrast, all students rapidly gained the skills to undertake blood gas sampling and were able to write oxygen prescriptions based on $\mathrm{SpO} 2$ results.

\section{Abstract P75 Table 1 Pass rates related to number of attempts}

\begin{tabular}{lrrrrrrrrrr}
\hline Attempts & 1 & 2 & 3 & 4 & 5 & 6 & 7 & 8 & 9 & 10 \\
Numbers passing & 92 & 36 & 3 & 12 & 15 & 1 & 15 & 6 & 10 & 52 \\
Cumulative \% & 27 & 38 & 39 & 43 & 47 & 47 & 52 & 54 & 56 & 72 \\
\hline
\end{tabular}

Conclusions This study confirms that medical students, like other staff, have a poor basic knowledge about the use of emergency oxygen. The Liverpool PSP is addressing this knowledge gap but in view of the results further education (eg, seminars and e-learning) will be provided prior to the CBKT. We recommend this type of programme to other Medical Schools and clinical staff.

\section{Paediatric asthma}

\section{P76 LONG-TERM EFFECTIVENESS OF A STAGED ASSESSMENT FOR PROBLEMATIC SEVERE ASTHIMA}

doi:10.1136/thoraxjnl-2011-201054c.76

${ }^{1} \mathrm{~J}$ Sharples, ${ }^{1} \mathrm{~A}$ Gupta, ${ }^{1} \mathrm{~L}$ Fleming, ${ }^{1} \mathrm{C}$ J Bossley, ${ }^{2} \mathrm{M}$ Bracken, ${ }^{2} \mathrm{P}$ Hall, ${ }^{2} \mathrm{~A}$ Hayward, ${ }^{3} \mathrm{M}$ Puckey, ${ }^{1} \mathrm{I} \mathrm{M}$ Balfour-Lynn, ${ }^{1} \mathrm{M}$ Rosenthal, ${ }^{1} \mathrm{~A}$ Bush, ${ }^{1} \mathrm{~S}$ Saglani. ${ }^{1}$ Department of Paediatric Respiratory Medicine, Royal Brompton Hospital, and Imperial College London, London, UK; ${ }^{2}$ Department of Respiratory Paediatrics, Royal Brompton Hospital, London, UK; ${ }^{3}$ Department of Clinical Psychology, Royal Brompton Hospital, London, UK

Background Children with problematic severe asthma (PA) may have genuine therapy-resistant disease, or may be difficult-to-treat because of unaddressed potentially modifiable factors.

Objectives Evaluate the long-term efficacy of a structured protocol including a nurse-led assessment ${ }^{1}$ (Stage 1) in identifying modifiable factors and differentiating difficult asthma (DA) from severe therapy-resistant asthma (STRA) in children with PA. As a secondary aim, we determined whether DA and STRA could be identified without the detailed assessment.

Methods 78 children, median age 11.8 years (range $5-17$ years), that underwent Stage 1 assessment between 2005 and 2008 were included. Lung function, medications, symptoms and exacerbations were obtained at 1 year, 2 years, and up to 6 years (current status) after initial assessment. Children in whom modifiable factors were identified were classified as DA and those that progressed to further investigations (Stages $2 \& 3$ ) as STRA.

Results Median duration of follow-up was 3.9 years (range 2.5-6.1 years). 31/78 (40\%) children were classified as DA, and did not proceed to Stages $2 \& 3$. Children with DA had significantly lower dose inhaled corticosteroids prescribed at follow-up compared to STRA (DA vs STRA: median [IOR] $800 \mu \mathrm{g}$ [400 $\mu \mathrm{g}-1425 \mu \mathrm{g}$ ] vs $1600 \mu \mathrm{g}[800 \mu \mathrm{g}-2400 \mu \mathrm{g}], \mathrm{p}<0.05)$, and significantly fewer oral corticosteroid bursts per year (DA vs STRA: median [IOR] 1 [0-2] vs 4 [1.5-8], $\mathrm{p}<0.001)$. DA children had improved lung function at follow-up compared to baseline (median [IOR] $\mathrm{FEV}_{1} \%$ predicted: 91\% [86.5\%-102.5\%] vs 80\% [73\%-86\%], p<0.01) despite lower dose inhaled corticosteroids. DA and STRA had different characteristics at baseline: DA children had a higher $\mathrm{FEV}_{1} \%$ predicted $(p<0.01)$, less bronchodilator reversibility $(p<0.05)$, lower fractional exhaled nitric oxide $(p<0.05)$, and less sensitisation to food and aeroallergens (both $p<0.05$ ) compared to STRA. However, there was considerable overlap between the groups and the two could not reliably be distinguished in advance of the detailed Stage 1 assessment.

Conclusion As a result of our assessment, $40 \%$ of children with PA did not undergo invasive investigations and escalation of therapy. Up to 6 years later, children with DA had a significant improvement in lung function and fewer exacerbations despite reduced maintenance medication.

\section{REFERENCE}

1. Bracken M, et al. Arch Dis Child 2009;94:780-4.

\section{P77 LUNG CLEARANCE INDEX (LCI) IN CHILDREN WITH SEVERE, THERAPY RESISTANT ASTHMA (STRA)}

doi:10.1136/thoraxjnl-2011-201054c.77

${ }^{1} \mathrm{~S}$ Irving, ${ }^{2} \mathrm{~A}$ Bush, ${ }^{2} \mathrm{C}$ Bossley, ${ }^{2} \mathrm{~A}$ Gupta, ${ }^{2} \mathrm{~S}$ Saglani. ${ }^{1}$ Royal Brompton and Harefield NHS Foundation Trust, London, UK; ${ }^{2}$ National Heart and Lung Institute, Imperial College, London, UK

Introduction Spirometry is often normal in children with STRA, and is thus a poor outcome measure (1). Lung Clearance Index is a sensitive, non-effort dependent measure of distal airway gas mixing, which has been shown to be more sensitive than spirometry in Cystic Fibrosis (2). We hypothesised that LCI would be a better marker of steroid response in STRA than spirometry.

Patients and Methods 22 STRA children (Mean age 11.9 years, 15 male) had LCI and spirometry measured before and 4 weeks after intramuscular triamcinolone.

Results LCI was elevated in $18 / 22$ prior to triamcinolone and $12 / 22$ at the follow-up; in contrast FEV 1 was only abnormal in 10/22 and $6 / 22$ pretriamcinolone and posttriamcinolone respectively. Mean LCI fell from 7.86 to $7.25(\mathrm{p}<0.05)$ but there was no statistically significant decrease in $\mathrm{FEV}_{1}$ after triamcinolone.

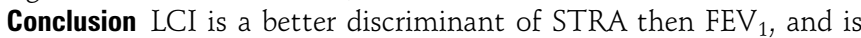
more responsive to steroid treatment. LCI may thus be a better outcome measure in STRA.

\section{Abstract P77 Table}

\begin{tabular}{lll}
\hline & Pre-triamcinolone & $\begin{array}{l}\text { 4 weeks } \\
\text { post-triamcinolone }\end{array}$ \\
\hline Mean $\mathrm{FEV}_{1}$ z-score (normal $\left.>-1.64\right)$ & -1.39 (SD 2.02) & -1.15 (SD 1.22) \\
Mean LCl (normal $<7.1)$ & 7.86 (SD 1.18) & 7.25 (SD 1.44) \\
\hline
\end{tabular}

\section{REFERENCES}

1. Bacharier LB, Strunk RC, Mauger D, et al. Classifying asthma severity in children: mismatch between symptoms, medication use, and lung function. Am J Respir Crit Care Med 2004;170:426-32.

2. Gustafsson PM, De Jong PA, Tiddens HA, et al. Multiple-breath inert gas washout and spirometry versus structural lung disease in cystic fibrosis. Thorax 2008; 63:129-34

\section{P78 LUNG CLEARANCE INDEX IN CHILDREN WITH ACUTE EXACERBATION OF ASTHMA}

doi:10.1136/thoraxjnl-2011-201054c.78

H S Sheridan, S Cunningham. Edinburgh University, Edinburgh, UK

Introduction Lung clearance index (LCI) can detect small airways disease in asthma; however there is no published LCI data collected 